\title{
High-Resolution Black Blood Vessel Wall Imaging in COVID-19 Encephalopathy_-Is it Really Endotheliitis?
}

\author{
Konstanze V. Guggenberger ${ }^{1}$ Thorsten A. Bley ${ }^{1} \cdot$ Marius L. Vogt ${ }^{2} \cdot$ Horst Urbach ${ }^{3} \cdot$ Stephan Meckel ${ }^{3,4}$
}

Received: 9 August 2021 / Accepted: 29 September 2021 / Published online: 28 October 2021

(c) The Author(s) 2021

\section{Dear Editor,}

with interest we read the study by Uginet et al. "Cerebrovascular Complications and Vessel Wall Imaging in COVID19 Encephalopathy-A Pilot Study" [1]. They described the findings on high-resolution black blood vessel wall magnetic resonance imaging (MRI) at $1.5 \mathrm{~T}$ that was performed in 34 older patients ( $66.5 \pm 9.2$ years; $10.3 \%$ female) with coronavirus diseases 2019 (COVID-19) and acute encephalopathy in a retrospective observational study.

The authors reported circumferential vessel wall enhancement in $85 \%$ (29/34) patients located in the intracranial vertebral and basilar arteries. The longitudinal extension of this vessel wall enhancement was described between $4.0 \mathrm{~mm}$ and $42.0 \mathrm{~mm}(18.0 \pm 9.76 \mathrm{~mm})$ and affected both vertebral arteries in $50 \%$ of patients. No associated stenosis of the affected vessels was seen on MR angiography.

The authors concluded that these findings were suggestive of endotheliitis and supportive of an inflammatory origin of COVID-19 encephalopathy; however, they could not demonstrate any association between vessel wall enhancement and ischemic brain lesions, severity of encephalopathy, measured by the confusion assessment method (CAM)

Konstanze V. Guggenberger

Guggenberg_K@ukw.de

1 Department of Diagnostic and Interventional Radiology, University Hospital Würzburg, University of Würzburg, Oberdürrbacher Str. 6, 97080 Wirtzburg, Germany

2 Department of Diagnostic and Interventional Neuroradiology, University Hospital Würzburg, University of Würzburg, Josef-Schneider-Straße 11, 97080 Wirtzburg, Germany

3 Department of Neuroradiology, Medical Center, University of Freiburg, Breisacher Straße 64, 79106 Freiburg, Germany

4 Institute of Neuroradiology, Kepler University Hospital, Johannes Kepler University Linz, Linz, Austria scale, or the presence of microbleeds on susceptibilityweighted images. Most importantly, neither histopathological correlation from any of their patients nor a control group of age-matched patients without COVID-19 encephalopathy was presented. Given these limitations, such conclusion cannot be drawn from their descriptive study findings.

To account for their study findings, intracranial vasa vasorum, developing with advancing age, typically causing concentric mural contrast enhancement and vessel wall thickening in vessel wall imaging using black-blood MRI [2], need to be considered. This type of vessel wall enhancement is frequently found on MRI vessel wall images in older subjects along the proximal intracranial vessel segments [3] after the vessels' dural crossing and may be easily mistaken for inflammatory changes, such as vasculitis. In our recently published study, we analyzed 43 older (mean age 71 years, SD 10 years) subjects without any clinical or laboratory signs of vasculitis and found concentric vessel wall enhancement of the proximal intradural vertebral artery in 39 patients (91\%) [4]. Mean longitudinal extension of vessel wall enhancement after dural entry was $13 \mathrm{~mm}$ (range $0-52 \mathrm{~mm}$ ) in the vertebral artery (right vertebral artery mean $12 \mathrm{~mm}$, range $0-34 \mathrm{~mm}$, left vertebral artery $14 \mathrm{~mm}$, range $0-52 \mathrm{~mm}$ ).

The reported images showing vessel wall enhancement of the proximal vertebral arteries (left vertebral artery in Fig. 1d and Fig 2a-c; bilateral vertebral arteries in Fig. 3d) of the addressed study [1] resemble the appearance of high-resolution vessel wall images from our non-vasculitic cohort (Fig. 2a-c, Fig. 3b in [4]): concentric vessel wall enhancement and slight vessel wall thickening of the nonstenotic vertebral artery in its proximal intradural course. This finding most likely represents vasa vasorum related vessel wall enhancement and should not be misinterpreted as inflammatory affection. Previous histopathologic and imaging studies have revealed results that support the presence of vasa vasorum causing these vessel wall imaging findings [3, 5-7]. 
We do not intend to refute the results of the addressed study but rather draw attention to the fact that vasa vasorum may constitute a potential confounder in diagnosing endotheliitis or intracranial vasculitis. Vessel wall enhancement in the proximal intradural vessel segments, in particular affecting the proximal vertebral arteries, is a common finding in non-vasculitic older patients without any pathologic significance. Supportive of this interpretation is the fact that COVID-19 related cerebral endotheliitis was hitherto described in small intracerebral vessels in a histopathological study [8].

Funding Open Access funding enabled and organized by Projekt DEAL.

Conflict of interest S. Meckel: Bracco S.p.A.: research grant (money paid to institution). Novartis Pharma GmbH: research grant (money paid to institution); consultant. K.V. Guggenberger, T.A. Bley, M.L. Vogt and H. Urbach declare that they have no competing interests.

Open Access This article is licensed under a Creative Commons Attribution 4.0 International License, which permits use, sharing, adaptation, distribution and reproduction in any medium or format, as long as you give appropriate credit to the original author(s) and the source, provide a link to the Creative Commons licence, and indicate if changes were made. The images or other third party material in this article are included in the article's Creative Commons licence, unless indicated otherwise in a credit line to the material. If material is not included in the article's Creative Commons licence and your intended use is not permitted by statutory regulation or exceeds the permitted use, you will need to obtain permission directly from the copyright holder. To view a copy of this licence, visit http://creativecommons.org/licenses/by/4. $0 /$.

\section{References}

1. Uginet M, Breville G, Hofmeister J, Machi P, Lalive PH, Rosi A, Fitsiori A, Vargas MI, Assal F, Allali G, Lovblad KO. Cerebrovas- cular Complications and Vessel Wall Imaging in COVID-19 Encephalopathy-A Pilot Study. Clin Neuroradiol. 2021. https://doi. org/10.1007/s00062-021-01008-2. Epub ahead of print.

2. Aoki S, Shirouzu I, Sasaki Y, Okubo T, Hayashi N, Machida T, Hoshi E, Suzuki K, Funada N, Araki T. Enhancement of the intracranial arterial wall at MR imaging: relationship to cerebral atherosclerosis. Radiology. 1995;194:477-81.

3. Takaba M, Endo S, Kurimoto M, Kuwayama N, Nishijima M, Takaku A. Vasa vasorum of the intracranial arteries. Acta Neurochir (Wien). 1998;140:411-6.

4. Guggenberger KV, Torre GD, Ludwig U, Vogel P, Weng AM, Vogt ML, Fröhlich M, Schmalzing M, Raithel E, Forman C, Urbach H, Meckel S, Bley TA. Vasa vasorum of proximal cerebral arteries after dural crossing - potential imaging confounder in diagnosing intracranial vasculitis in elderly subjects on blackblood MRI. Eur Radiol. 2021. https://doi.org/10.1007/s00330-02108181-5. Epub ahead of print.

5. Atkinson JL, Okazaki H, Sundt TM Jr, Nichols DA, Rufenacht DA. Intracranial cerebrovascular vasa vasorum associated with atherosclerosis and large thick-walled aneurysms. Surg Neurol. 1991;36:365-9.

6. Portanova A, Hakakian N, Mikulis DJ, Virmani R, Abdalla WM, Wasserman BA. Intracranial vasa vasorum: insights and implications for imaging. Radiology. 2013;267:667-79.

7. Mandell DM, Mossa-Basha M, Qiao Y, Hess CP, Hui F, Matouk C, Johnson MH, Daemen MJ, Vossough A, Edjlali M, Saloner D, Ansari SA, Wasserman BA, Mikulis DJ; Vessel Wall Imaging Study Group of the American Society of Neuroradiology. Intracranial Vessel Wall MRI: Principles and Expert Consensus Recommendations of the American Society of Neuroradiology. AJNR Am J Neuroradiol. 2017;38:218-29.

8. Kirschenbaum D, Imbach LL, Rushing EJ, Frauenknecht KBM, Gascho D, Ineichen BV, Keller E, Kohler S, Lichtblau M, Reimann RR, Schreib K, Ulrich S, Steiger P, Aguzzi A, Frontzek K. Intracerebral endotheliitis and microbleeds are neuropathological features of COVID-19. Neuropathol Appl Neurobiol. 2021;47: 454-9. 